\title{
Surface Structures and Osteoclasts of Mouse Parietal Bones: A Light and Scanning Electron Microscopic Study
}

\author{
Kazuhiro ABE, Taiki Kanno and Gary B. SchneIder \\ Department of Anatomy, Hokkaido University School of Medicine, Sapporo, Japan and Department of \\ Anatomy, Loyola University Medical Center, Maywood, Illinois, U. S. A.
}

Received December 23, 1982

Summary. The resorption surface caused by osteoclasts are identified by scanning electron microscopy (SEM), but the morphological interrelation between these resorption surfaces and Howship's lacunae observed by light microscopy remains obscure, and little evidence showing that the distribution and structures of the resorption surface change according to the function of osteoclasts is available. To understand the relationship between the function of osteoclasts and the morphological evidence of bone resorption, surface structures of the parietal bones in mice, newborn to adult, were studied by SEM. The osteoclasts on the inner surface of the calvaria are considered to be involved in the growth of the skull.

The outer surface of the parietal bone was smooth, whereas the inner surface consisted of both smooth and rough areas. The rough areas were usually much larger than Howship's lacunae, which are generally thought to be of osteoclast size. These areas were composed of small and shallow concavities with oval or polygonal outlines. The borders between adjacent concavities appeared as ridges. The rough areas were very wide in the growing skull and osteoclasts were scattered on these wide rough areas. The osteoclasts were much larger than the concavities in the rough areas. During the growth of the skull, the proportion of rough areas occupying the inner surface changed parallel to the number of osteoclasts, which varied in correspondence with the growth rate of the skull. The maximum value of the proportion was about $60 \%$ at 1 week of age.

The findings suggest that the osteoclasts resorb the bone by moving along its surface, forming small concavities and leaving rough areas larger than Howship's lacunae of osteoclast size. Furthermore, they suggest that the size and distribution of the rough areas and the morphological features of the concavities in the rough areas vary depending upon the activities of the osteoclasts.

Osteoclastes are multinucleated giant cells seen on the surface of bone where bone resorption is occurring and, together with osteoblasts, contribute to the modeling of bones during bone development or repair of bone injuries (see reviews by GöTHLIN and Ericsson, 1976; Holtrop and King, 1977; Ham and Cormack, 1979; Bonucci, 1981). Osteoclasts are usually located in Howship's lacunae, which are formed by bone resorption.

Since about 150 years ago the name of Howship's lacunae has been applied to indentations produced on the bone surface during the bone resorption, and these lacunae 
are bordered with sharp edges by normal bone and believed to be formed by osteoclasts; they roughly correspond in size to osteoclasts (see review by JAFFE, 1930). In this paper, a bone surface depression of osteoclast size or a slightly larger one which is demonstrated by light microscopy as a shape deserving the term of "lacuna" will be called Howship's lacuna, whereas the term resorption surface or area is used in generally referring to unevenness, including the Howship's lacuna, formed by bone resorption.

The bone resorption surfaces are considered to very according to the functional activities of the osteoclasts and can be identified under the scanning electron microscope (SEM) (Boyde and Hobdell, 1969a, b; Anderson and Danylchuk, 1977; Dillaman et al., 1979; KREMPIEN, 1979). Therefore, scanning electron microscopy (SEM) is considered to indicate Howship's lacunae, suggesting the distribution and activities of osteoclasts dissolving the bone matrix. However, structures indicated as Howship's lacunae in the previous SEM studies appear different depending on investigators (BOYDE and Hobdell, 1969a, b; Anderson and Danylchuck, 1977; Dillaman et al., 1979; Krempien, 1979), and little is known about whether or not the distribution and structures of resorption surfaces change in relation to the function of osteoclasts.

To study the function of osteoclasts, metaphyseal trabeculae of long bones and the inner surface of plate bones of the skull in young animals have often been observed, because these sites contain abundant osteoclasts for the continuous modeling which occurs while the bones are growing (Bingham et al., 1969; Marks, 1973; Tatevossian, 1973). In particular, the plate bones of the skull show the processes of bone formation and resorption on their surfaces which can be easily exposed; these bones are suited to the study of osteoclast activity using SEM. The resorption areas on these plate bones are thought to change in distribution and structure during the growth of the skull. BARNICOT (1947) had demonstrated age-related changes in distribution and number of osteoclasts on the mouse parietal bones under the dissecting microscope. In this study, we examined surface structures of the mouse parietal bones by SEM, in order to understand the relationship between the function of osteoclasts and morphology of the resorption areas during the development of the skull. To compare to the distribution of the resorption surfaces, the number and distribution of osteoclasts on the bones were verified by light microscopy.

\section{MATERIALS AND METHODS}

In this study, 58 dd-mice were used. The mice were killed at 1 day, 1, 2, 3, 4, 8 and 17 weeks of age. The body weight, width of the skull, and weight of the whole brains of 4 to 5 mice of each age were measured. To obtain the width of the skull, the skull was exposed by removing the skin, and the largest width was measured at right angles to the sagittal plane of the skull using slide calipers.

For light microscopy, the calvaria with attached dura was removed, fixed in Bouin's solution for $6 \mathrm{hrs}$, decalcified in $6 \%$ nitric acid for 1 to 3 days, and embedded in paraffin. Frontal cross sections of the skull were serially cut at $6 \mu \mathrm{m}$, stained with hematoxylin and eosin, and observed by light microscopy. For one skull at 1 day, 1,2 and 3 weeks of age, the number of osteoclasts on the parietal bones was counted in 20 sections selected at an interval of $60 \mu \mathrm{m}$, and then the number per $\mathrm{cm}$ of the lateral aspect of the bone was obtained.

For SEM observation of the bone surface, the calvaria was cleaned by removing the periostium and dura using fine forceps and a small rubber policeman under the 
dissecting microscope, and immersed in 5\% sodium hypochloride solution for 15 to 30 sec to remove organic material. The bone was washed with water, dehydrated by acetone, air-dried, attached to an aluminum stub, coated with gold using an iron-coater, and observed in the SEM. For quantitation, photographs covering the whole area of the inner and outer surfaces of the parietal bones were taken at $50 \times$ or $100 \times$ to obtain the proportions of smooth and rough areas on the surfaces.

To observe the cells attached to the bone surface, the skulls at 1 day, 1 and 8 weeks of age were fixed with $2 \%$ glutaraldehyde in $0.1 \mathrm{M}$ cacodylate buffer for $1 \mathrm{hr}$. The periosteum and dura were immersed in 3\% tannic acid for $6 \mathrm{hrs}$, and fixed in $\mathrm{OsO}_{4}$ for $2 \mathrm{hrs}$. The bone was dehydrated in a graded series of alcohol, immersed in isoamyl acetate, and critical point-dried in $\mathrm{CO}_{2}$. The skull was attached to an aluminum stub, coated with gold, and examined by the SEM.

\section{RESULTS}

\section{Body weight, width of the skull, and brain weight (Fig. 1)}

The body weight increased linearly until 4 weeks after birth, and thereafter showed a gradual increase. The width of the skull and the brain weight increased rapidly during the first 2 weeks after birth, and slightly during the third week, reaching a plateau thereafter.

\section{Light microscopy}

In newborn and 1 week-old mice, the outer surface of the parietal bones was covered with many osteoblasts which were mononuclear and had basophilic cytoplasm (Fig. 2). The inner surface had a lesser concentration of osteoclasts than those on the outer surface. Osteoclasts, multinucleated giant cells lying on the bone surface, were seen on the inner surface, but few or none were found on the outer surface (Fig. 2). The bone surface adjacent to osteoclasts occasionally showed shallow depressions, although irregular depressions not associated with osteoclasts were also observed on the surface.

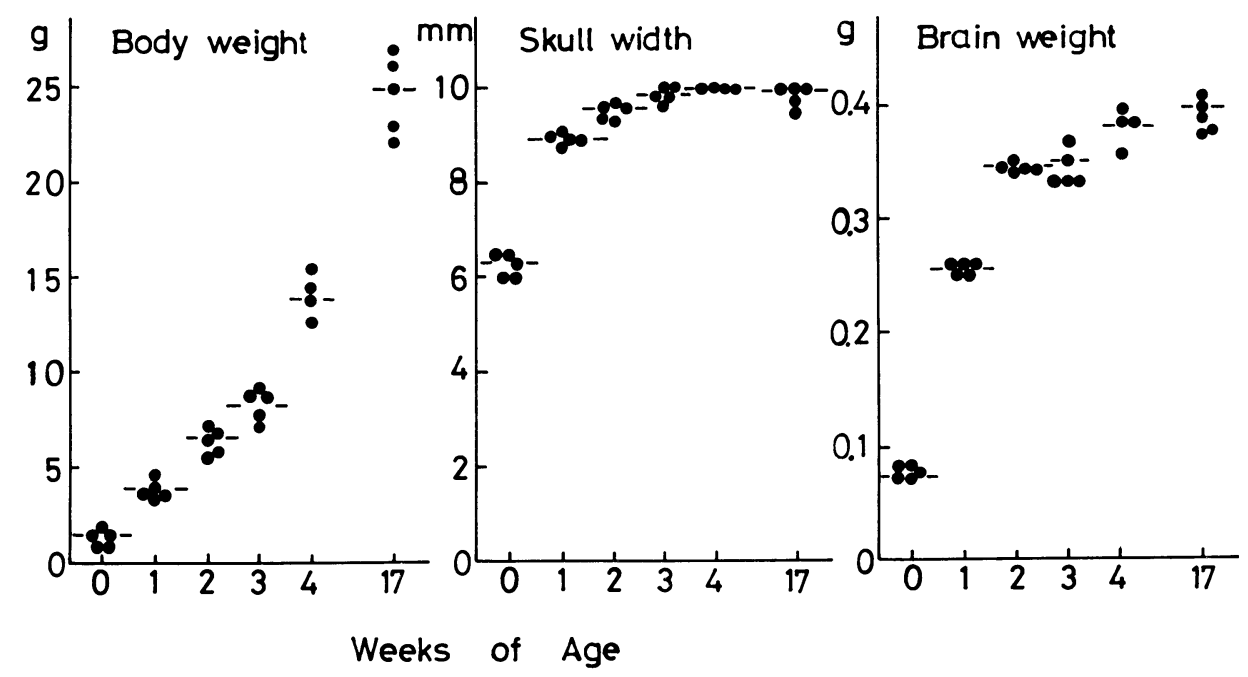

Fig. 1. Body weight, skull width, and brain weight at various weeks of age. 
As shown in Figure 3, many osteoclasts were observed on the inner surface at 1 day and 1 week of age, but they became scare at 3 weeks and hardly detectable after 4 weeks of age.

Quantitatively, the number of osteoclasts on the inner surface was $14.1 / \mathrm{cm}$ of the lateral aspect of the bone at 1 day, increased to $16.9 / \mathrm{cm}$ at 1 week, then declined, and became $1.6 / \mathrm{cm}$ at 3 weeks of age (Fig. 4). In contrast, osteoclasts on the outer surface counted 0.2 to $2.1 / \mathrm{cm}$ during this time span.

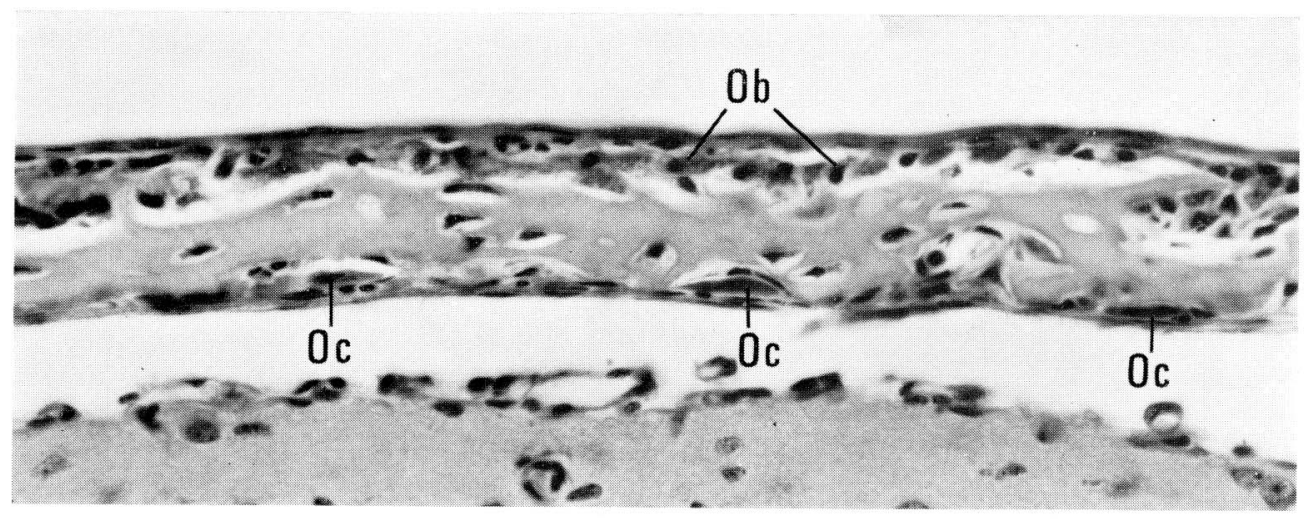

Fig. 2. Light micrograph of the parietal bone at 1 week of age. Many osteoblasts ( $O b$ ) cover the outer surface of the bone. Osteoclasts $(O c)$ are seen on the inner surface. Two osteoclasts (left and middle) are located in shallow depressions, but no depression is associated with the osteoclasts at the right. Depressions without osteoclasts are also seen on the inner surface. Hematoxylin-eosin. $\times 550$

0

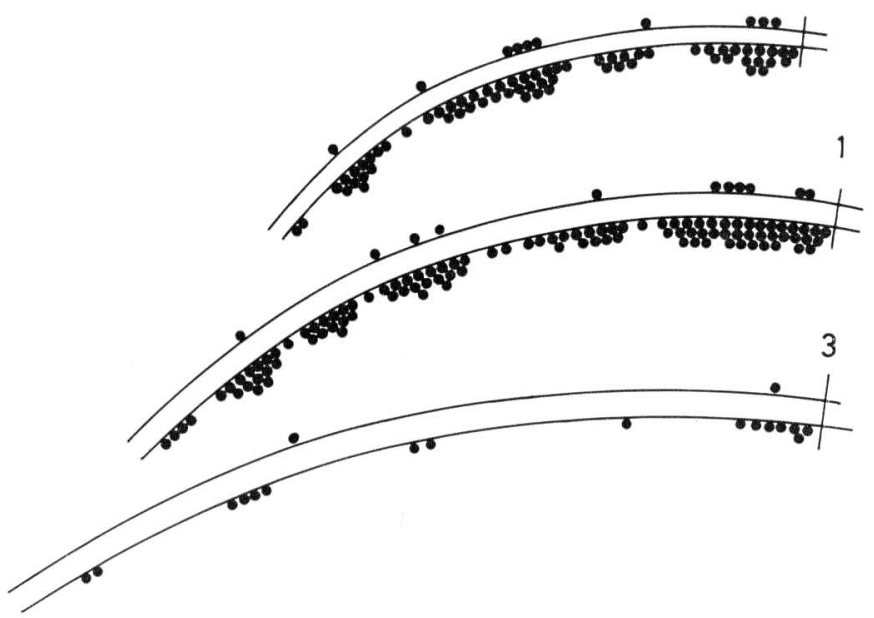

Fig. 3. Diagram showing distribution of osteoclasts (black dots) on the parietal bones of newborn (0), 1 week-old ( 1 ), and 3 week-old (3) mice. Osteoclasts on the outer surface (above) and inner surface (below) in 20 sections of each parietal bone were superimposed on the drawing. Lines at the numbers indicate the position of sagittal sutures. 


\section{Scanning electron microscopy}

At 1 week of age, the bone surface from which the soft tissues had been removed revealed smooth and rough areas (Fig. 5,6). The outer surface of the parietal bone consisted mainly of smooth areas showing a smooth surface (Fig. 5). Round or oval and shallow osteoblast lacunae, 10 to $25 \mu \mathrm{m}$ in diameter, were scattered throughout the smooth areas. The bottom of the lacunae was usually flat and showed 10 to 30 pits, about 0.2 to $0.5 \mu \mathrm{m}$ in diameter (Fig. $5 \mathrm{~b}$ ). Such pits were also scattered on the smooth surface (Fig. 5b). Round openings of vascular canals, about 20 to $50 \mu \mathrm{m}$ in diameter, were seen on the surface (Fig. 5). The rough areas on the outer surface were rare and if found, were small.

The inner surface at 1 week also consisted of smooth and rough areas (Fig. 6). The smooth areas appeared similar to those on the outer surface. The rough areas were usually very large and overall occupied a much larger proportion of the inner surface

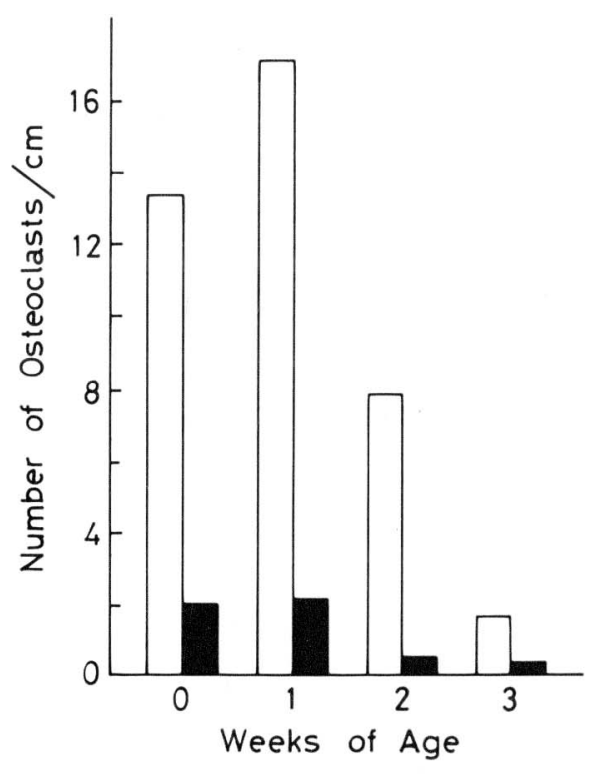

Fig. 4. Number of osteoclasts on the inner surface (white bars) and outer surface (black bars) of the parietal bone.
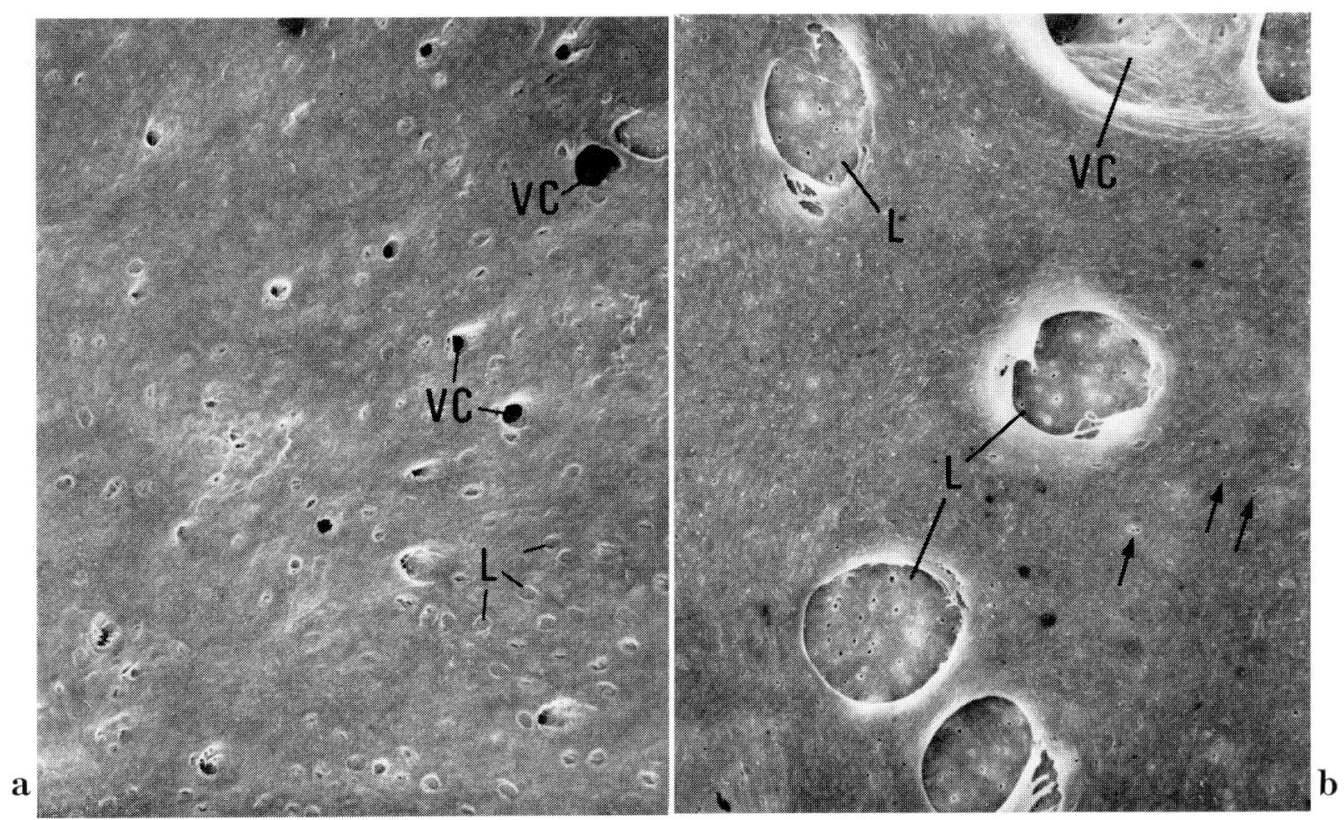

Fig. 5. SEM images of the outer surface of the parietal bone at 1 week of age. The soft tissue has been removed. a. The outer surface is mainly smooth. Round openings of vascular canals $(V C)$ and scattering small osteoblast lacunae $(L)$ are seen on the smooth surface. $\times 180$. b. In closer view, the osteoblast lacunae $(L)$ show flat bottoms with many pits. Fine pits are also seen on the smooth area (arrows). $V C$ opening of a vascular canal. $\times 1,500$ 

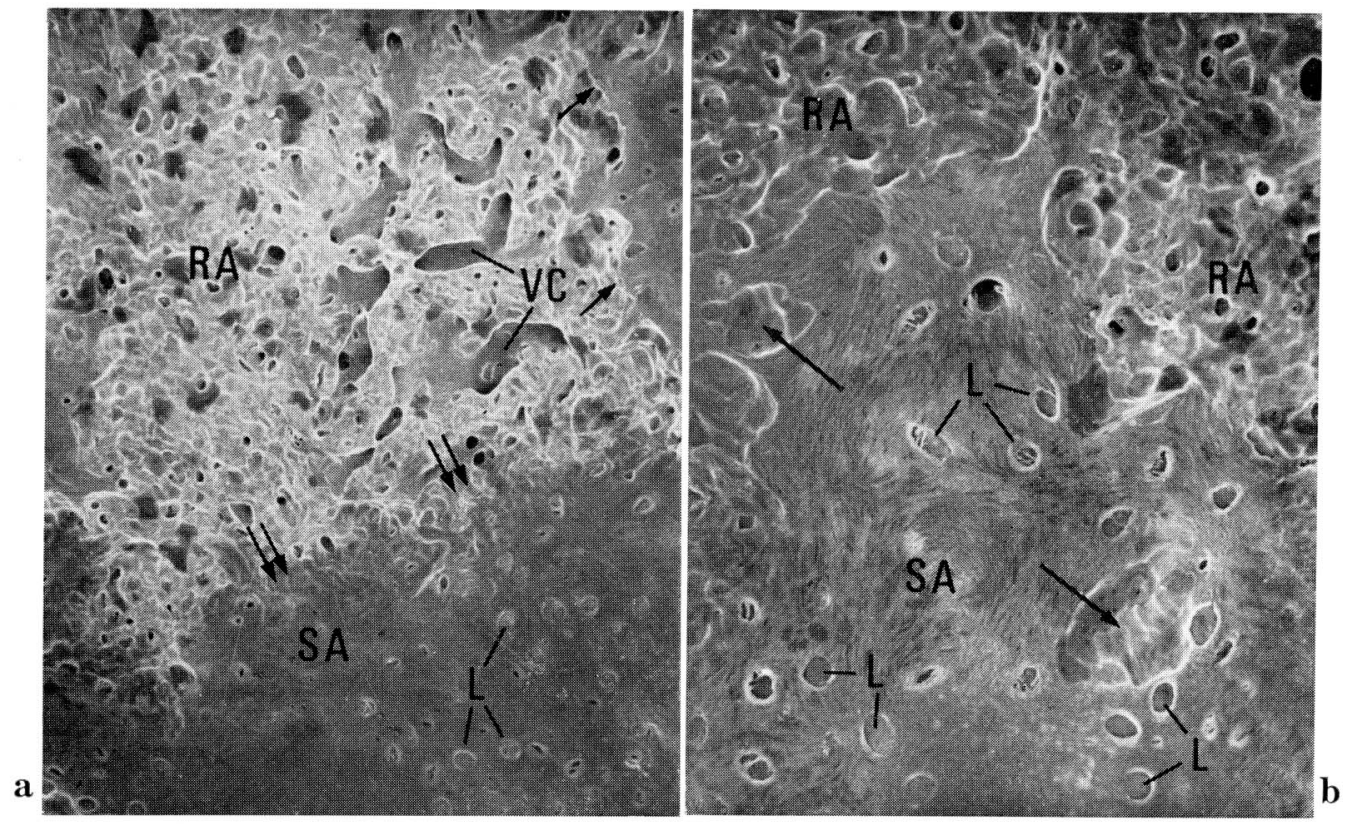

Fig. 6. Inner surface of the parietal bone at 1 week of age. The soft tissue has been removed. $R A$ rough area, $S A$ smooth area, $L$ osteoblast lacunae. a. The right margin (arrows) of the rough area appears sharp but the lower margin (double arrows) appears obscure because of gradual transition from the rough to smooth areas. Exposed vascular canals (VC) are seen in the rough area. $\times 190$. b. The borders between the smooth $(S A)$ and rough areas $(R A)$ are clearly delineated, the latter consisting of irregular concavities. Small rough areas (arrows) also consists of several concavities. $\times 360$

than that of the outer surface. The rough area consisted of a group of shallow concavities of oval, polygonal or irregular outline (Fig. 6-8). The concavities were 8 to $30 \mu \mathrm{m}$ wide. The borders between adjacent concavities appeared as low but rather sharp ridges (Fig. 6b, 7). The ridges were observed more clearly at the periphery than the central region of each area (Fig. $6 b, 7 b, c)$. The bottom of each concavity was fibrous, granular or smooth (Fig. 7b, c).

Small rough areas were scattered around the larger rough areas (Fig. 6b). The smallest of these was about $40 \mu \mathrm{m}$ wide. These small rough areas were also composed of several concavities.

In the rough areas, branching vascular canals were exposed (Fig. 6a, 7a). Their inner surface were smooth and showed many pits, about 0.2 to $0.5 \mu \mathrm{m}$ in diameter. Round or oval cavities, which corresponded to osteocyte lacunae opened, were scattered throughout the rough areas (Fig. 7, 8a). The bottoms had many fine pits, as seen in the osteoblast lacunae on the smooth areas.

The borders between the rough and smooth areas, in general, were clearly delineated and showed irregular bay-like configurations due to peripheral concavities of the rough areas (Fig. $6,7 \mathrm{~b}, \mathrm{c}$ ). The margin of the rough areas formed sharp depressions in the smooth surface of the smooth areas (Fig. 7b, c). Occasionally, there were obscure borders showing gradual transformation from the smooth to the rough area (Fig. 6a).

During the development of the skull, the rough areas were usually well demarked, 

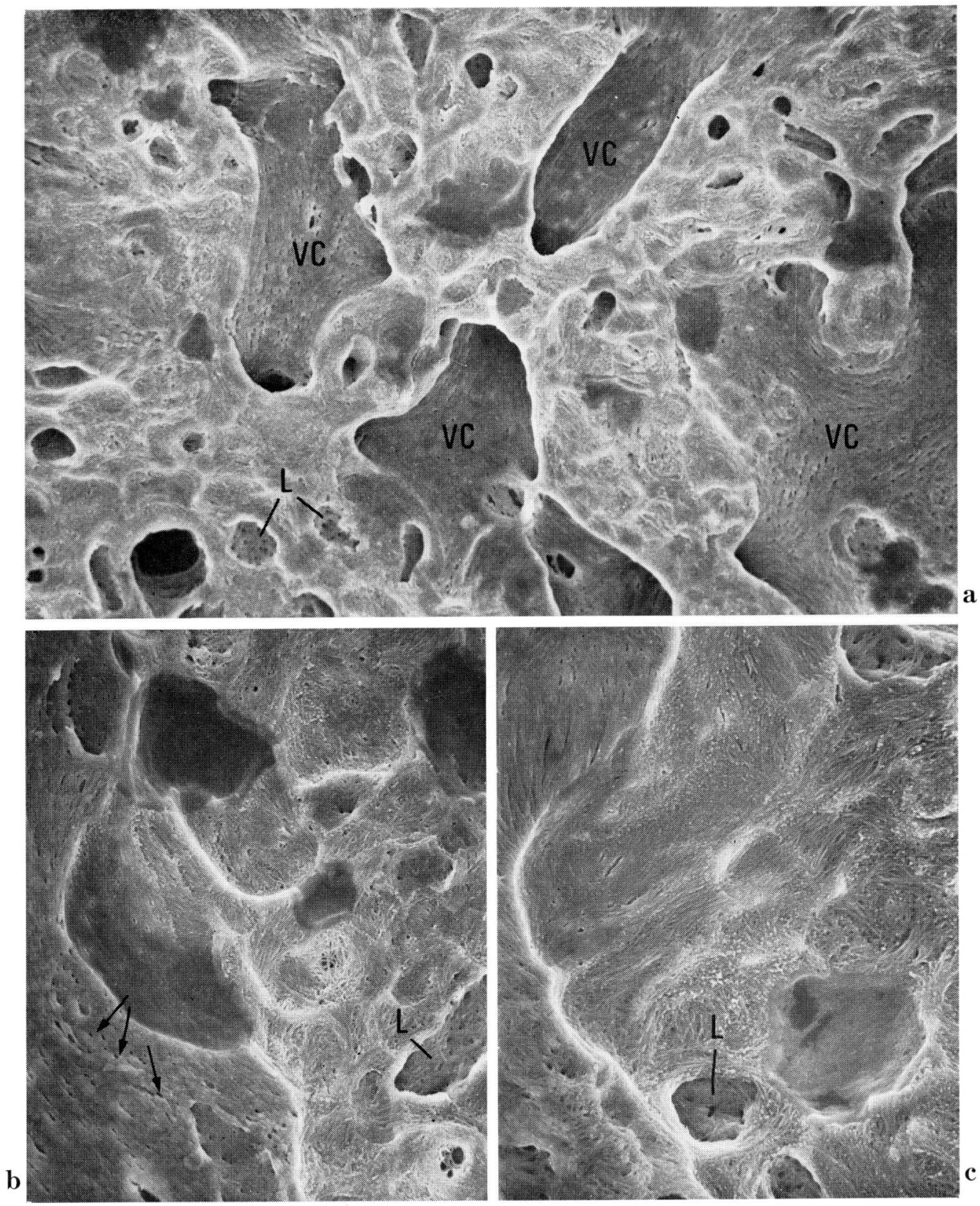

Fig. 7. Inner surface of the parietal bone at 1 week of age. The soft tissue has been removed. a. Rough area. Exposed vascular canals $(V C)$ show many fine pits on their inner surfaces. Osteocyte lacunae $(L)$ also show several pits. $\times 100$. b. and $\mathbf{c}$. The border between the smooth area (left) and rough area (right) is clearly delineated. Concavities making up the rough areas reveal fibrous, granular, or smooth bottoms. Fine pits are seen on the smooth areas (arrows) and in the osteocyte lacunae $(L)$ on the rough areas. b: $\times 1,500, \mathrm{c}: \times 1,700$ 

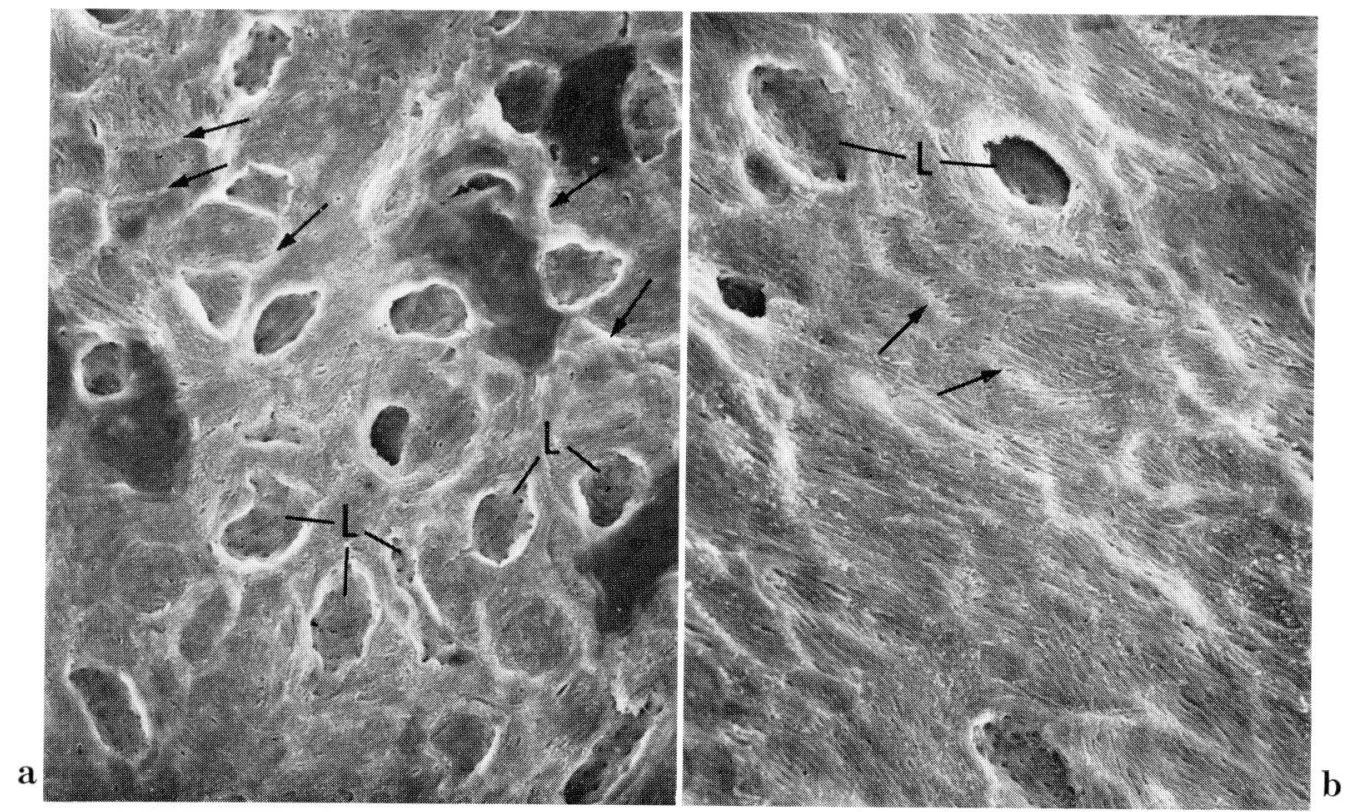

Fig. 8. Central regions of the rough areas on the inner surface of the parietal bone. The soft tissue has been removed. a. 1 week of age. Ridges bounding the concavities are obvious (arrows). Many osteocyte lacunae $(L)$ with fine pits are scattered. $\times 1,000 . \quad$ b. 2 weeks of age. Ridges (arrows) separating concavities are rounded and obscure. $L$ osteocyte lacunae. $\times 1,400$

as described above. However, in the rough areas except for their periphery, the ridges bounding the concavities became rounded and obscure at 2 weeks of age (Fig. 8).

Distribution and proportion of the rough and smooth areas (Fig. 9, 10): In newborn mice, the central region of the inner surface of the parietal bones was occupied by a large rough area. This area surrounded a small smooth central area. The peripheral region of the bones showed a wide rim of the smooth area. At 1 week of age, the central rough area was enlarged and the peripheral smooth area became narrower. At 2 weeks, the smooth area in the central region of the central rough area became larger and connected with the peripheral smooth area surrounding the rough area. A few smooth areas appeared also in the rough area. After 3 weeks, the rough areas on the inner surface were separated and became small and scarce. The rough areas on the outer surface were rarely detected through the growth of the skull.

The proportion of the rough areas occupying the inner surface was about $40 \%$ at the day of birth, about $60 \%$ at 1 to 2 weeks, and below $10 \%$ after 3 weeks. In contrast, the rough areas on the outer surface were below $5 \%$ from newborn to adult.

Cells on the skull bones: At 1 day and 1 week of age, the outer surface of the parietal bones was covered with densely packed osteoblasts, which were about $20 \mu \mathrm{m}$ in diameter (Fig. 11b). On the inner surface, dense accumulations of osteoblasts were occasionally seen at the peripheral region of the bone, but usually osteoblasts were sparcely scattered. In contrast, many osteoclasts were seen on the inner surface of the bone except for the peripheral region where osteoblasts were found (Fig. 11a). Osteoclasts were irregular in configuration due to irregular dendritic processes. The width of the cell bodies of the large osteoclasts were about $60 \mu \mathrm{m}$; and the longest dimension, from one end of a cytoplasmic process to the other end was about $200 \mu \mathrm{m}$. Osteoclasts 


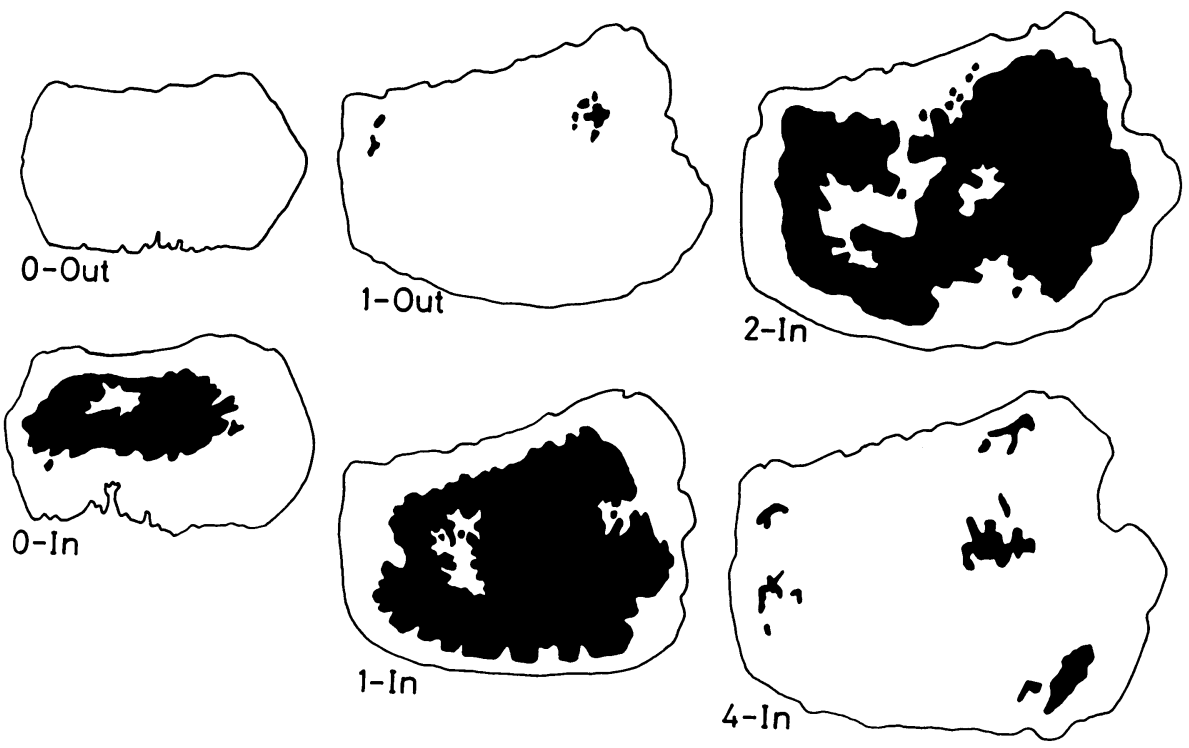

Fig. 9. Drawings representing the distribution of the smooth areas (white) and rough areas (black) on the inner ( In) and outer (Out) surfaces of the parietal bones at the day of birth (0), 1, 2, and 4 weeks of age. Upper and right edges of each parietal bone directs to the frontal bone and sagittal suture, respectively. $\times 10$

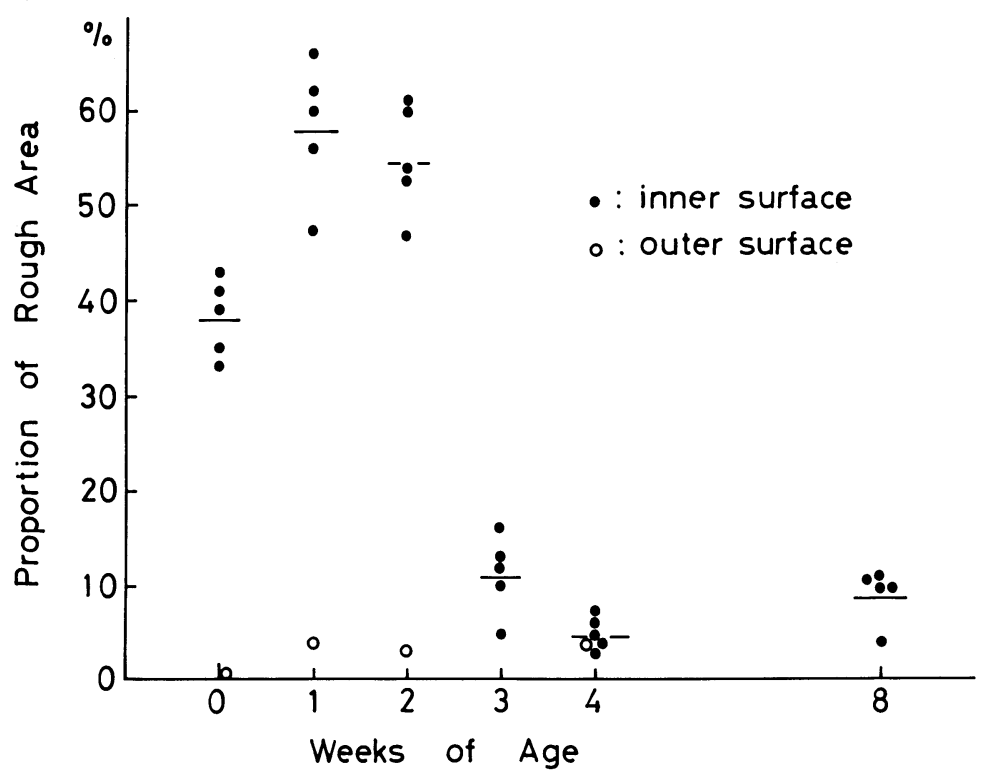

Fig. 10. Proportion of the rough areas on the parietal bone at various weeks of age. Bars represent mean values of the rough areas on the inner surface. 


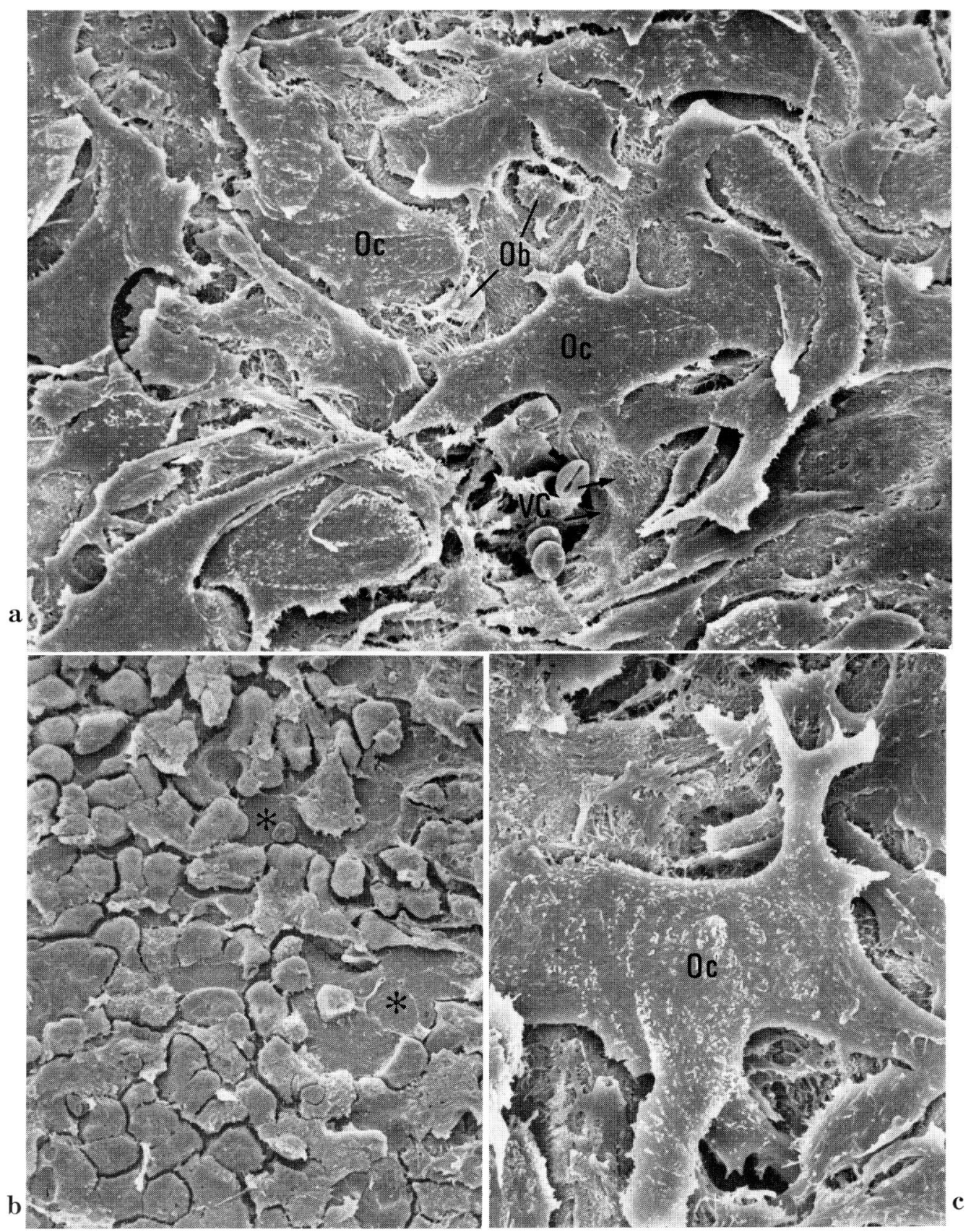

Fig. 11. SEM images of the cells on the surface of the parietal bone at 1 week of age. a. Inner surface. Many osteoclasts $(O c)$ are seen. Osteoclasts are very large compared with osteoblastic cells $(O b)$ and have dendritic processes. Concavities (arrows) of the rough bone surface are visible near a vascular canal $(V C) . \times 1,200 . \quad$ b. Outer surface covered with many osteoblasts. Desquamation of the cells reveals the surface of bone matrix $(*) . \times 700$ c. Inner surface. An osteoclast $(O c)$ is shown. $\times 2,300$ 


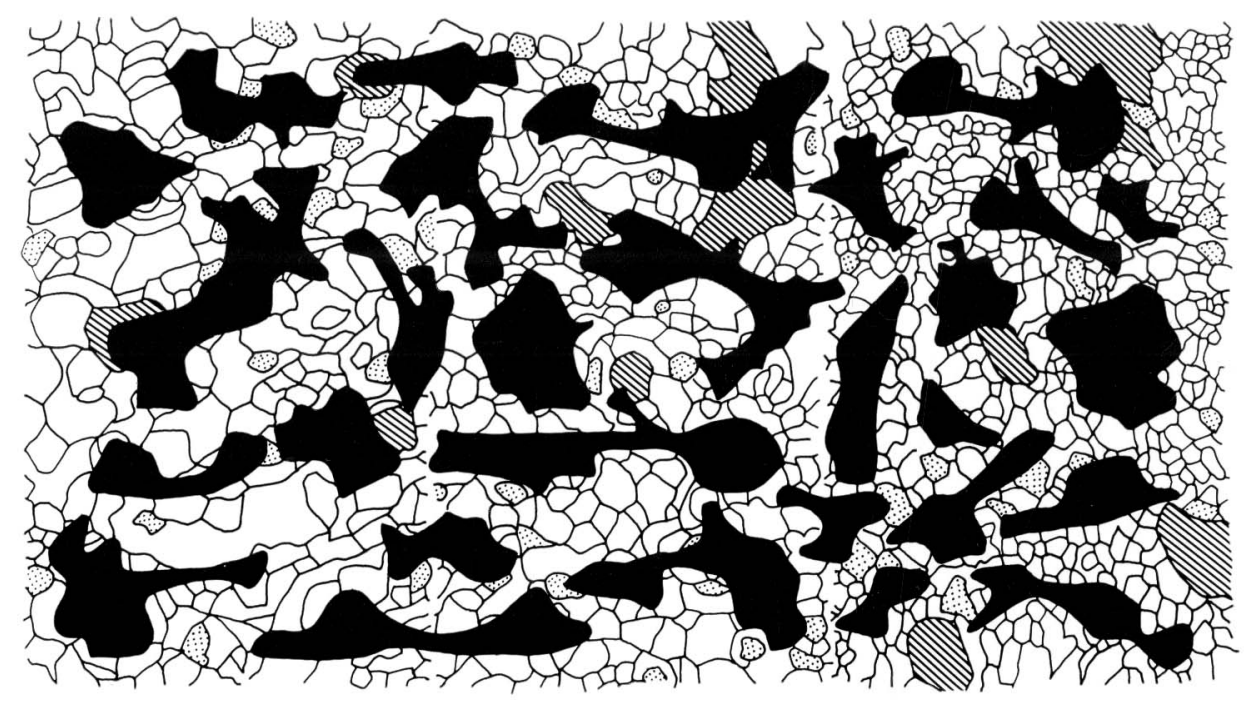

Fig. 12. Diagram comparing the size of concavities making up the rough area (white) and the size of osteoclasts (black). The outline of concavities was traced out along the ridges bounding them. This diagram was composed from the drawings of three different areas (left, middle, and right). Osteoclasts in still other rough areas were drawn (black) and superimposed on the drawing of the concavities. Osteocyte-lacunae are dotted, and vascular canals are shaded. $\times 200$

were located primarily over the rough areas. The size of concavities in the rough areas were smaller than that of the cell bodies and corresponded to the width of their cytoplasmic processes (Fig. 12). The surface at 8 weeks of age had osteoblastic cells but very few osteoclasts.

\section{DISCUSSION}

As generally accepted, growing bones of the skull show bone formation on the outer surface and bone resorption on the inner surface. Osteoclasts are distributed on the inner surface, and they may form Howship's lacunae when they resorb bone. By light microscopy, these lacunae can be observed as depressions containing osteoclasts on the bone surface. By SEM, the inner surface of the parietal bones showed a broad expanse of rough areas. From previous studies and our own observations (Boyde and Hobdell, 1969a, b; Anderson and Danylchuck, 1977; Dillaman et al., 1979; Krempien, 1979), these rough areas are believed to be produced by bone resorption. However, some investigators demonstrated small rough areas composed of several concavities as Howship's lacunae (ANDERSON and DANYLCHUCK, 1977), whereas concavities within the rough areas were shown as Howship's lacunae by others (Boyde and Hobdell, 1969a, b; Dillaman et al., 1979). Thus, the morphological relationship between Howship's lacunae observed by light microscopy and those by SEM has been ambiguous.

As shown in Results, concavities in the rough areas were much smaller than osteoclasts, and small rough areas, made up of several concavities, corresponded in size to osteoclasts. This suggests that an osteoclast forms several concavities within a Howship's lacuna. In the inner surface of the parietal bones, on the other hand, the 
rough areas of osteoclast-size were rare and usually very wide, and osteoclasts were scattered on these wide rough areas. Therefore, osteoclasts are presumed to dissolve the bone by moving along the bone surface, leaving the rough areas as traces of their activity. In the lateral aspect of a sectioned bone seen by light microscopy, only small indentations containing osteoclasts may be identified as Howship's lacunae, and it is generally difficult to recognize the rough areas which are much broader than the former.

The width of the concavities in the rough areas was similar to that of the dendritic processes of osteoclasts. Osteoclasts resorb the bone matrix at the sites of their ruffled borders, and the ruffled borders are encircled by a clear zone which acts as a site of attachment to the bone surface (see reviews by Göthlin and Ericsson, 1976; HoltroP and KING, 1977). Though not evidenced, it may be possible that an osteoclast has several ruffled borders and these are variable in number and size during the bone resorption. Each concavitiy within a rough area may possibly be formed by each of the ruffled borders.

However, the concavites were also as large as mononuclear cells, like osteoblasts. Boyde and HoBdell (1969a) considered that the smallest concavities were caused by mononuclear cells. Could the mononuclear cells have formed these concavities? Multinucleated osteoclasts are thought to be made by fusion of mononuclear phagocytic cells (Coccia et al., 1980; Bonucci, 1981). Mononucleated or binucleated preosteoclasts were observed on fetal rat carvarium by transmission electron micrscopy, but these cells lacked ruffled borders and it is unknown whether or not they can absorb the bone (RIFKIN et al., 1980); recent studies in vitro have demonstrated that mononuclear macrophages can resorb bone matrix, but it remains unknown what kinds of resorbing bays are formed by macrophages (MUNDY et al., 1977; KAHN et al., 1978; RIFKIN et al., 1979). In any case, according to our SEM observations, small cells of osteoblast-size did not appear to produce the rough areas or concavities of the rough areas.

The distribution pattern of the rough areas on the inner surface of the parietal bones was similar to that of osteoclasts which had been demonstrated by BARNICOT (1947) who, using the dissecting microscope, examined the age-related distribution and number of osteoclasts, stained supravitally with neutral red, on the mouse parietal bones. The distribution of the rough areas suggests that peripheral regions of parietal bones are bone formation sites and the central areas are involved in remodeling by bone resorption.

The proportion of the rough areas, as well as the number of osteoclasts, on the inner surface may change according to bone dissolving activity. The number of osteoclasts obtained in this study corresponded to those by BARNicoT (1947). When our results are combined with Barnicot's it can be seen that the changes in the number of osteoclasts did not parallel the changes in the body weight but appeared directly related to the growth of the skull, which corresponds to the growth of the brain. The number of osteoclasts on the skull increased for 1 week after birth, when the skull was growing rapidly. As the growth rate decreased from 1 to 3 weeks of age, the number of osteoclasts decreased and the osteoclasts became very rare after 3 weeks, when the growth of the skull ceased.

The proportion of the rough areas occupying the inner surface of the parietal bones changes nearly in parallel to the number of osteoclasts with age. Actively growing bones are active in bone resorption as well as bone formation. However, from 1 to 2 weeks of age, despite a decrease in number of osteoclasts, the proportion of the rough areas did not change. This suggests that the rough areas remains for 
about one week after the disappearance of osteoclasts. The fact that the ridges at the borders between the concavities in the rough area are less pronounced at 2 weeks yields evidence of a decrease in bone resorption. Thus, detailed examinations of surface structures in the rough areas may be worth while in evaluating the bone resorptive activity. The bottoms of the concavities look variable in details.

In conclusion, SEM observations suggest that osteoclasts, as the result of their bone absorbing activity, form larger rough areas rather than Howship's lacunae corresponding in size to these cells, and that the size and distribution of the rough areas and the morphological features of the concavities making up the rough areas are important as indicators of the functional activities of osteoclasts. The small rough area which coincides with Howship's lacuna is essentially the same in character as the large rough area. The terminology of Howship's lacunae in SEM needs reconsideration.

Acknowledgement. We wish to thank the Department of Orthopedic Surgery, Hokkaido University School of Medicine, for the support for this study.

\section{REFERENCES}

Anderson, C. and K. D. Danylchuk: Scanning electron microscopic observations on bone. Arch. Pathol. lab. Med. 101: 19-21 (1977).

Barnicot, N. A.: The supravital staining of osteoclasts with neutral red: their distribution on the parietal bone of normal growing mice, and a comparison with the mutants grew lethal and hydrocephalus-3. Proc. Roy. Soc. B. 134: 467-485 (1947).

Bingham, P. J., I. A. Brazell and M. Owen: The effect of parathyroid extract on cellular activity and plasma calcium level in vivo. J. Endocrinol. 45: 387-400 (1969).

Bonucci, E.: New knowledge on the origin, function and fate of osteoclasts. Clin. Orthop. 158: 252269 (1981).

Boyde, A. and M. H. Hobdell : Scanning electron microscopy of lammelar bone. Z. Zellforsch. 93: 213-231 (1969a).

- Scanning electron microscopy of primiary membrane bone. Z. Zellforsch. 99: 98-100 (1969b).

Coccia, P. T., W. Krivit, J. Cerven Ka, C, Clawson, J, H. Kersey, T. H. Kim, M. E. Nesbit, N, K. C. Ramsay, P. I. Warkentin, S. L., Teitelbaum. A. J. Kahn and D. M. Brown: Successful bone-marrow transplantation for infantile malignant osteopetrosis. New. Engl. J. Med. 302: 701-708 (1980).

Dillaman, R. M., K. M. Wilbur and M. A. Crenshaw : Growth of embryonic chick tibiae in ovo and in vitro: A scanning electron microscope study. Calcif. Tiss. Intern. 27: 33-40 (1979).

Göthlin, G. and J. L. E. Ericsson : The osteoclasts. Review of ultrastructure, origin, and structurefunction relationship. Clin. Orthop. 120: 201-231 (1976).

Ham, A. W. and D. H. Cormack : Histology of cartilage, bone, and joints. Lippincott, Philadelphia, 1979.

Holtrop, M. E. and G. J. King : The ultrastructure of the osteoclast and its functional implications. Clin. Orthop. 123: 177-196 (1977).

Jaffe, H. L.: The resorption of bone. A consideration of the underlying processes particularly in pathologic conditions. Arch. Surg. 20: 354-385 (1930).

Kahn, A. J., C. C. Stewart and S. L. Teitelbaum: Contact-mediated bone resorption by human monocytes in vitro. Science 199: 988-990 (1978).

Krempien, B.: Bone modeling processes at the endosteal surface of human femora. Scanning electron microscopical studies in normal bone and in renal osteodystrophy. Virchows Arch. A Pathol. Anat. Histol. 382: 73-88 (1979). 
Marks, S. C., Jr.: Pathogenesis of osteopetrosis in the ia rat: Reduced bone resorption due to reduced osteoclasts function. Amer. J. Anat. 138: 165-190 (1973).

Mundy, G. R., A. J. Altman, M. D. Gonadek and D. Bandelin : Direct resorption of bone by human monocytes. Science 196: 1109-1111 (1977).

Rifkin, B. R., R. L. Baker and S. J. Coleman : An ultrastructural study of macrophage-mediated resorption of calcified tissue. Cell Tiss. Res. 202: 125-132 (1979).

Rifkin, B. R., J. S. Brand, J. E. Cushing, S. J. Coleman and F. Sanavi : Fine structure of fetal rat carvarium; provisional identification of preosteoclasts. Calcif. Tiss. Int. 31: 21-28 (1980).

Tatevossian, A.: Effect of parathyroid extract on blood calcium and osteoclast count in mice. Calcif. Tiss. Res. 11: 251-257 (1973).

阿部和厚

干060 札幌市北区北15条西 7 丁目

北海道大学医学部

解剖学第三講座
Dr. Kazuhiro ABE

Department of Anatomy

Hokkaido University School of Medicine

Sapporo, 060 Japan 